The patient improved most satisfactorily up to the 25th, when her husband summoned me in haste, stating that his wife was dying. I found her gasping for breath; pulse at the wrist scarcely perceptible; had complained of great pain in the chest. Apply turpentine stupes to the chest; hot bottles to the feet, and give one drachm of brandy. Nutrients more frequently; continue diuretic mixture and brandy.

29th. - The patient was delirious last night; got out of bed, and went into the adjoining room. This morning she is nervous and fidgety. Pulse 120, weak. Half an ounce of brandy every two hours; continue diuretic; twenty minims of tincture of opium at bedtime.

30th. -Slept well last night; much improved; dropsy disappearing, except in face and legs; urine much increased, clear. She called my attention to a swelling in the right iliac region, for which she had been previously under treatment. Now that the ascites was removed, I perceived a tumour in this situation, of the size of a large fist; painful; movable; outline distinct; fuctuation perceptible. As vaginal examination was objected to, I did not press it in her present state, intending, however, to do so at a future time. To apply six leeches, and fomentation.

June 1st. - Pain in iliac region removed. Apply six more leeches.

6th. - At this time all the more urgent symptoms had disappeared, but the legs became enormously distended, and covered with one mass of petechiæ. The catamenia reappeared; excessive and pale. Discontinue the diuretic mixture. The legs to be bandaged. Ten minims of tincture of muriate of iron thrice a day.

From this time the patient recovered most rapidly, the bloated cheeks, however, remained unchanged, showing that the cure was not yet complete. Ordered to bandage the face tightly with handkerchiefs, and to continue the iron. In a few days my patient had the satisfaction of seeing her face reduced to its normal proportions. The eczema entirely disappeared, and by the end of June she had not only regained her strength, but stated that she never felt better in her life. I now pressed for an examination of the swelling in the side, when she assured me, that after a minute examination, not a vestige remained.

Here was a case of acute pulmonary odema, supervening on chronic ascites and general anasarca, in a patient debilitated by long disease and inability to take substantial food. Her history was most unpromising, her brother having died of dropsy, her mother dropsical, and a sister, abont whom $I$ have since been consulted, in the same state. To a young prac titioner like myself, it may be supposed that the case was one of no little anxiety. But still, after a most minute examination, being satisfied that no organic disease existed, and believing in the wonderful power of drugs when properly employed, I predicted a perfect recovery. But when the ascites had disappeared, and my attention was called to the tumour in the ilia region, my favourable prognosis was shaken. Had I continued the routine practice with diuretics, not only should I have failed in effecting a cure, but I anticipated a return of all the symptoms which had disappeared. What diuretics failed in, iron accomplished, and has, I believe, rendered permanent a cure, which would otherwise have been of short duration. What would nature-what would the much-vaunted homoopathy have done in such a case? Allowed disease to have its sway, and hurry the poor patient with rapid and unerring strides to a premature and unnecessary death. Upon what pathological condition did the dropsical effision in this case depend? Doubtless the more liquid portions of this greatly impoverished blood found a ready exit through the walls of the capillaries, relaxed from want of their proper stimulus-a healthy blood. The action of the iron is then obvious.

And now comes the most important question. What was the tumour in the iliac region? Could it be ovarian dropsy Such was my diagnosis. But we are told that the contents of an ovarian cyst are never absorbed. The vaginal walls, however, may give way, and the contents be discharged by that channel. Was the supposed return, then, of the catamenia on the 6th of June such a discharge? I think it possible; but as a vaginal examination was not made, a doubt may exist whether the tumour was ovarian at all. Here is a tumour dating from a miscarriage ten years ago, gradually rising out of the pelvic cavity towards the abdomen, increasing as it proceeds; at times painful; movable; with defined outline and perceptible fluctuation. I ask, if not an ovarian tumour, what was it ?

The extracts I have made of this case seemed to me as few as were compatible with the right understanding of so important a subject.

Angust, 1860
PFPORT OF A

\section{CASE OF FISSURE OF THE ANUS.}

\author{
BY W. P. IARRIS, M.D.,
}

ASSISTAXT-SURGEOY, 15TH REGT. PUYJAUS INFANTRT PIONETRS.

THE following account of a recent case of fissure of the anus which I have had under treatment has been transmitted by me in the belief that it contains points of practical interest to the profession at large.

J. B-, engineer, Viscount Canning transport steam-ship, commenced to suffer from severe burning pain during defeca. tion in the early part of March, 1860, during the stay of his ship in Calcutta. $\mathrm{He}_{e}$ is a square-built, dark-complexioned, healthyllooking man, and states that he has always enjoyed good health, but that, in consequence of disagreement with some of the other officers of the ship, he drank more than usual during his stay in Calcutta. No sooner had I taken medical charge of the ship, than he applied to me, stating that his sufferings were extreme, and that they had been increasing during the last three weeks. He had frequent calls to stool, passing small freal motions mixed with a little slimy-looking matter, attended with severe burning and aching pain; his appetite was bad, and his countenance expressive of much anxiety and suffering.

In the first place, satisfying myself of the absence of piles, and that most common East Indian disease, dysentery, I at once suspected the cause of the suffering, verifying my diagnosis by ocular and manual demonstrations, upon which I saw and felt a condition of disease of which, I believe, very little is known by many members of the profession, especially by the junior portion, for whose guidance this article is principally written. The only abnormal appearances of the diseased parts in which such intense suffering occurred were: a congested bluish appearance without swelling; no hardening of the skin, but a crack half an inch long behind the anus, looking like a simple clean incision in the skin; and, on examination by means of the finger introduced into the rectum, a slight roughening of the mucous membrane, in a circular form, was felt on the hinder part of the bowel just above the sphinoter-an nlcer, from which, during defecation, matter was discharged, though not to any appreciable amount during the intervali.

Looking upon the etiology of the disease in this case to be congestion of the liver, and the cause of the pain to be stretch. ing of the fissure and ulcer, as well as of the congested, highly sensitive venous structures about the anus, $I$ adopted the fol lowing treatment:- I first relieved the venous system and congested state of the liver by means of one or two doses of mercurials, followed by small doses of saline purgatives continned for three days. During this period $I$ applied locally to the parts, externally and internally, in the neighbourhood of the anus, an astringent ointment, imagining that I might perhaps cure the disease thus, without the aid of the knife; but although a little relief was afforded,--partially, I think, from the discontinnance of "Cockle's" pills, which he had been taking daily,-yet after the lapse of a couple of days the case became stationary, no progress towards cure continuing, and the aspect of my patient still denoting great anxiety and suffering. I therefore at once determined to use the knife. I inserted a probe-pointed bistoury, on the forefinger of the right hand, within the sphincter, cutting outwards to the extent of about a quarter of an inch, tbrough the sphincter, during which I incised slightly both the nlcer and fissure.

The operation is so simple and comparatively painless, that no chloroform or manual assistance is required, nor need bleeding be feared.

After this little operation, I restrained the action of the bowels for a few days, keeping the incision open by means of tents daily applied. After the lapse of three or four days, his bowels acted without the least suffering, and the cure was completed, by means of nitrate of silver ointment and constitutional remedies, within ten days.

My excuse for troubling the readers of THE LANCET with a case of so common a disease as fissure of the anus is, that although a complaint attended by intense suffering and ready cure, the profession, and especially the junior portion of it, are not so alert at the detection of this malady as they are in the diagnosis of other classes of sickness.

Camp Rowloon, Hong Kong, May, 1860. 